\title{
CYSTIC MYXOMATOUS DEGENERATION OF POPLITEAL ARTERY
}

\author{
B. P. BLISS, F.R.C.S. \\ BY \\ Registrar to the Professorial Surgical Unit \\ J. RHODES, M.B., F.F.R. \\ Senior Registrar, Radiodiagnostic Department
}

A. J. HARDING RAINS, M.S., F.R.C.S.

Professor of Surgery; Honorary Consultant Surgeon, Charing Cross and Fulham Hospitals

\section{From Charing Cross Hospital, London}

Hiertonn, Lindberg, and Rob (1957) described the first four cases of a disease characterized by the formation of a mucin-containing cyst within the wall of the popliteal artery producing arterial obstruction. One of their cases had been reported previously (Ejrup and Hiertonn, 1954), and they quoted another case described by Atkins and Key (1947) of what may have been a similar condition involving the external iliac artery. Since then five more cases involving the popliteal artery have been described, and a further case is mentioned by Sutton (1962).

The cardinal features common to their cases were described by Hiertonn and Lindberg (1957) as: (1) occurrence in young males; (2) sudden onset with cramps in the calf ; (3) development of intermittent claudication; (4) local stenosis and/or occlusion of the popliteal artery ; (5) absence of generalized arterial changes ; (6) intramural cyst formation between media and adventitia compressing the arterial lumen; (7) cyst contents of gelatinous material under tension; (8) cyst walls lined by flattened cells; and (9) structure of cyst wall suggestive of mucinous degeneration.

The description of further cases has made revision of some of these features necessary.

This paper describes a further case of the condition, arising in a female, and reviews those cases reported in the literature.

\section{Case Report}

A housewife aged 40 was admitted to hospital in July, 1962. Four months previously, while walking on flat ground, she suddenly experienced cramping pain in the popliteal region and down the outer aspect of the calf of the left leg. She was able to continue walking slowly until reaching home. The foot was then cold and white but the symptoms passed off after resting for a short while. After this episode she experienced typical intermittent claudication in the left calf. Her claudication distance was about 200 yards (180 metres). The claudication pain was accompanied by pallor, coldness, and paraesthesiae in the left foot. The symptoms were not progressive but persisted unchanged. There was no history of trauma or of previous cardiovascular disease.

Examination showed her to be healthy and slightly obese. B.P. 125/75. At rest the legs and feet were warm and there was no detectable difference in temperature, colour, or nutrition on the two sides. Femoral, popliteal, posterior tibial, and dorsalis pedis pulses were palpable in both legs, though the left posterior tibial and dorsalis pedis pulses were slightly diminished. She was asked to walk quickly up four flights of stairs. This produced cramping pain in the left leg from mid-thigh to ankle. On examination immediately after exercise the left foot was cold and the toes were pale. The left posterior tibial and dorsalis pedis pulses were now only just palpable, and markedly diminished as compared with those on the right. The limb returned to normal after 15 to 20 minutes at rest.

Investigations.-Hb $14.1 \mathrm{~g} . / 100 \mathrm{ml}$. Chest $x$-ray examination normal. Fasting blood-sugar $92 \mathrm{mg} . / 100 \mathrm{ml}$. On July 4 an aortogram by right femoral catheterization showed some narrowing of the left popliteal artery, but the character of the narrowing was not adequately displayed. On July 9 a left femoral arteriogram showed a regular narrowing of the upper part of the left popliteal artery (see Fig.) about $3 \mathrm{~cm}$. in length apparently due to a smooth encroachment on the medial side of the vessel. The artery was not displaced. A collateral circulation had not developed, and there was no other evidence of arterial disease. The appearances were thought to be suggestive of cystic degeneration of the popliteal artery. It was decided to explore the artery.

Operation.-On July 17 the popliteal artery was displayed through an incision along the medial side of the left knee and thigh. Strong periarterial adhesions were present and a firm, elastic, and fusiform swelling, $5 \mathrm{~cm}$. in length, was found involving the upper part of the artery. Pulsation was present and normal above, but was markedly diminished in the swelling itself and below. Blood flow was interrupted by clips, and a longitudinal incision was made into the distended artery wall. Clear, colourless, jelly-like material was immediately extruded under pressure. About $5 \mathrm{ml}$. was removed, demonstrating an apparently intact artery within a cyst which appeared to surround the vesse! over three-quarters of its circumference. On releasing the clips there was immediate improvement in pulsation in the artery passing through the cyst. There remained, however, a band of periarterial adhesions, associated with a small medial branch of the popliteal artery, crossing the uppermost limit of the cyst. When this adhesion was divided full pulsations were restored, though a slight thrill was palpable. A portion of the superficial wall of the cyst was removed for histology. No attempt was made to resuture the incision into the cyst wall. The wound was then closed.
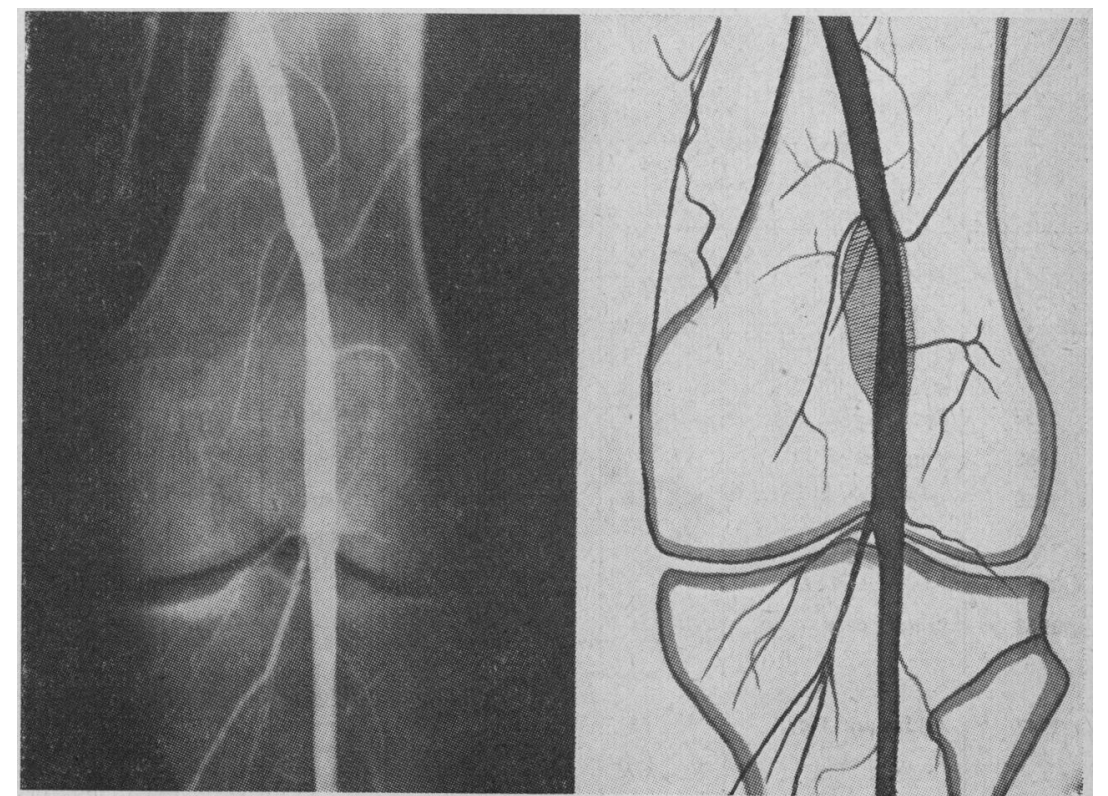

Left: Popliteal arteriogram showing site and character of the stenosis. Right: Drawing of the arteriogram with cyst superimposed (cross-hatched). 
Post-operative progress was uneventful, and the patient has remained symptom-free with no claudication in the short period since her discharge from hospital.

Histology.-The outer wall of the cyst was composed of dense fibrous tissue with a few longitudinally arranged elastic fibres and occasional small blood-vessels. No muscle was detected. The elastic fibres probably represent the external elastic lamina. It seems probable that the cyst arose in the superficial layers of the media and that medial fibrosis subsequently obliterated the muscle. No layer of flattened cells was seen lining the cyst wall in the specimen.

\section{Discussion}

A table of reported cases has been compiled for comparison of the main features which form the basis of the discussion.

\section{Aetiology}

The patients have all been adults, aged 24 to 50 , and most have been manual workers in heavy industry. Males outnumbered females by $4: 1$. Our case is only the second reported in a female.

Inflammation, haemorrhage, and trauma have been considered as possible aetiological factors. Dense periarterial adhesions have often been present, and histology of the cyst wall in one case (Hiertonn et al., 1957) showed infiltration with inflammatory cells. Hiertonn and Lindberg (1957) and Holmes (1960) believed these changes to be secondary, and excluded inflammation and haemorrhage on the basis of their histological and biochemical findings.

There being no definite traumatic incident, most authors have accepted repeated minor trauma as the most important aetiological factor. This being so it seems strange that the condition is so rare, especially in such groups as cyclists, athletes, miners, etc.

The sudden onset of symptoms is difficult to explain, since an intramural mucinous cyst is unlikely to appear suddenly. A possible explanation might be a sudden minute intramural dissection, giving rise to arterial spasm and followed by development of an effusion which subsequently becomes mucoid.

\section{Clinical Findings. Ishikawa's Sign}

The clinical signs in these patients were not diagnostic. However, Ishikawa et al. (1961), in their case with incom- plete arterial obstruction and normal findings at rest, found that full flexion of the knee produced pallor, coldness, and absent ankle pulses. This sign may prove diagnostic of the condition when the block is incomplete. The initial diagnosis in males is otherwise likely to be Buerger's disease, the differentiation being made later only by arteriography. All young claudicants should therefore have arteriographic examination.

\section{Arteriography}

Arteriography shows either a localized stenosis of varying severity or a segmental occlusion in the upper part of the popliteal artery.

A stenosis is seen as a unilateral, smooth filling defect or occasionally as an hour-glass deformity, without displacement of the artery. The remaining vessels appear normal, with no evidence of a collateral circulation. Presumably arterial insufficiency is intermittent and inadequate to stimulate collateral flow. The degree of stenosis may vary in a given patient. Thus of the two pre-operative arteriograms performed on our patient the first showed narrowing of the lumen by $50 \%$, while five days later narrowing was only $25 \%$. This may be postural, since Ishikawa et al. (1961) demonstrated in lateral arteriograms that full flexion of the knee caused accentuation of the stenosis together with change of the normal U-shape of the flexed artery to an $M$-shape, presumably due to the popliteal artery being kept locally more rigid by the encircling cyst.

Once occlusion has taken place there may be no specific local feature to suggest the diagnosis. However, Andersson et al. (1959) demonstrated a tapering of the upper end of the re-formed popliteal artery immediately below the block which when present is very suggestive of this condition. This appearance is due to compression of the arterial lumen by the lower part of the cyst. The occluded segment is usually short, with a good collateral circulation.

\section{Pathology}

There is a unilocular or multilocular mucin-containing cyst, sometimes enclosed by a membrane of flattened cells, lying within the superficial layers of the vessel wall. It may lie between the media and adventitia or, as in our case, within the superficial layers of the media.

\begin{tabular}{|c|c|c|c|c|c|c|c|c|c|c|}
\hline \multirow[b]{2}{*}{ Year } & \multirow[b]{2}{*}{ Authors } & \multicolumn{3}{|r|}{ Aetiology } & \multicolumn{3}{|c|}{ Clinical Features } & \multirow[b]{2}{*}{$\begin{array}{l}\text { Arteriogram } \\
\text { (Stenosis or } \\
\text { Occlusion) }\end{array}$} & \multirow{2}{*}{$\begin{array}{l}\text { Pathology } \\
\text { (Nature } \\
\text { of Cyst) }\end{array}$} & \multirow[b]{2}{*}{ Treatment } \\
\hline & & \multicolumn{2}{|c|}{$\begin{array}{l}\text { Age } \\
\text { and } \\
\text { Sex }\end{array}$} & Occupation & Onset & $\begin{array}{c}\text { Duration } \\
\text { of } \\
\text { Symptoms }\end{array}$ & $\begin{array}{c}\text { Inter- } \\
\text { mittent } \\
\text { Claudication }\end{array}$ & & & \\
\hline 1954 & Ejrup and Hierton & & $\mathbf{M}$ & Truck driver & Gradual & 6 months & Present & $\begin{array}{l}\text { Stenosis } \\
2 \mathrm{~cm}\end{array}$ & Multilocular & $\begin{array}{l}\text { Resection and autogenous } \\
\text { vein graft }\end{array}$ \\
\hline 1957 & $\begin{array}{c}\text { Hertonn et al. } \\
\text { " } ",\end{array}$ & & $\mathbf{M}$ & General labourer & Sudden & 6 weeks & ", & Occlusion & Unilocular & $\begin{array}{c}\text { Resection and arterial } \\
\text { homograft }\end{array}$ \\
\hline 1957 & , " , & & $\mathbf{M}$ & Clerk & ", & 9 months & , & Occlusion & ", & $\begin{array}{l}\text { Resection and autogenous } \\
\text { vein graft }\end{array}$ \\
\hline 1957 & ",$\quad$, & 32 & $\mathbf{M}$ & Iron-plate worker & ", & $4 \quad$ & , & , & $"$ & $\begin{array}{l}\text { Resection and autogenous } \\
\text { vein graft }\end{array}$ \\
\hline 1958 & Patel et al. & 50 & $\mathbf{F}$ & - & Gradual & - & $"$ & $\begin{array}{l}\text { Stenosis } \\
3-4 \mathrm{~cm}\end{array}$ & , & $\begin{array}{l}\text { Incision of cyst and } \\
\text { evacuation of contents }\end{array}$ \\
\hline 1958 & Tytgat et al. & 47 & $\mathbf{M}$ & $\begin{array}{l}\text { Roundsman using } \\
\text { pedal tricycle }\end{array}$ & Sudden & 1 week & ", & $\begin{array}{l}\text { Severe } \\
\text { stenosis }\end{array}$ & Multilocular & $\begin{array}{l}\text { Resection and replace- } \\
\text { ment with nylon graft }\end{array}$ \\
\hline 1959 & Andersson et al. & & $\mathbf{M}$ & Factory worker & - & 1 year & " & $\begin{array}{l}\text { Occlusion } \\
6 \mathrm{~cm} \text {. }\end{array}$ & Unilocular & $\begin{array}{l}\text { Resection and arterial } \\
\text { homograft }\end{array}$ \\
\hline 1960 & Holmes & 42 & $\mathbf{M}$ & Mechanic & Sudden & 6 weeks & ", & $\begin{array}{l}\text { Stenosis } \\
3-4-\mathrm{cm}\end{array}$ & Multilocular & $\begin{array}{l}\text { Cyst dissected from vessel } \\
\text { intact }\end{array}$ \\
\hline 1961 & Ishikawa et al. & 32 & $\mathbf{M}$ & Farmer & 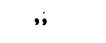 & 9 months & ", & $\begin{array}{l}\text { Stenosis } \\
2 \mathrm{~cm}\end{array}$ & ", & $\begin{array}{l}\text { Excision of cyst wall and } \\
\text { evacuation of contents }\end{array}$ \\
\hline 1963 & Present case & 40 & $\mathbf{F}$ & Housewife & $"$ & $4 \quad$ & $"$ & $\begin{array}{l}\text { Stenosis } \\
3 \mathrm{~cm}\end{array}$ & Unilocular & $\begin{array}{c}\text { Incision of cyst and } \\
\text { evacuation of contents }\end{array}$ \\
\hline & & & & A Similar $C$ & ondition $\mathrm{OC}_{c}$ & urring in Ex & ternal Iliac Art & & & \\
\hline 1947 & Atkins and Key & 40 & $\mathbf{M}$ & Policeman & - & 4 months & Present & - & $\begin{array}{l}\text { Multilocular } \\
\text { myxomatous } \\
\text { cyst of left } \\
\text { ext. iliac } \\
\text { artery }\end{array}$ & $\begin{array}{l}\text { Cyst dissected from vessel } \\
\text { and excised }\end{array}$ \\
\hline
\end{tabular}


In our patient it would not have been possible to dissect the cyst away from the vessel wall, but in two of the reported cases (Atkins and Key, 1947 ; Holmes, 1960) the cyst was enucleated substantially intact, the specimen resembling a myxoma or ganglion. We therefore prefer to call the disease "cystic myxomatous degeneration of the popliteal artery." The myxomatous type of case may represent a later stage in pathogenesis with development of a definite lining to the cyst wall.

\section{Treatment}

Where stenosis alone is present, without secondary thrombosis, either dissection and excision or incision and evacuation of the cyst is followed by return of normal pulsation and blood-flow.

Where obstruction due to the cyst has produced secondary thrombosis and a block of the arterial lumen either excision and grafting or thrombo-endarterectomy will be required. All reported cases to date have been grafted.

A five-year follow-up of these would be useful in order to know if evacuation leads to aneurysm formation and if grafts still remain patent. The case of Tytgat $e t$ al. (1958), in which recrudescence of symptoms occurred after four months, suggests that grafts may have a rate of failure similar to that found in atherosclerosis.

\section{Summary}

A case of cystic myxomatous degeneration of the popliteal artery is described. The literature on this condition is reviewed.

This is a rare cause of intermittent claudication in young adults which may be readily confused with Buerger's disease.
The cardinal features of the disease are:

Aetiology : It is a condition of unknown pathogenesis occurring in young adults, especially manual workers in heavy industry. Females are occasionally affected.

Clinical picture: The onset is sudden with cramps in the leg, followed by typical intermittent claudication. Signs of ischaemia are present and may be exacerbated by full flexion of the knee. Arteriography shows a smooth-walled stenosis or complete block in the popliteal artery with an otherwise normal arterial tree.

Pathology: A unilocular or multilocular mucincontaining cyst is present within the wall of the artery, compressing the lumen.

Treatment: In most cases evacuation of the cyst is sufficient. Thrombo-endarterectomy or excision and grafting may be necessary when secondary thrombosis of the lumen has occurred.

Prognosis: The immediate prognosis after surgical treatment appears to be excellent. The long-term prognosis is as yet unknown.

We wish to thank Mr. W. P. Greening, under whose care the initial investigations were performed, for permission to publish this case. We also thank Miss P. Turnbull for the medical photography.

\section{REFERENCES}

Andersson, T, Gothman, B., and Lindberg, K. (1959). Acta radiol. (Stockn.), 52, 455

Atkins, H. J. B., and Key, J. A. (1947). Brit. J. Surg., 34, 426.

Ejrup, B., and Hiertonn, T. (1954). Acta chir. scand., 108, 217.

Hiertonn, T., and Lindberg, K. (1957). Ibid., 113, 72.

Holmes, and Rob, C. (1957). Brit. J. Surg., 44, 348.

Ishikawa, K., Mishima, Y., and Kobayashi, S. (1961). Angiology, 12. 357 .

Patel, J., Facquet, J., and Piwnica, A. (1958). Presse méd., 66 , 1164 .

Sutton, D. (1962). Arteriography, p. 84. Livingstone, Edinburgh.

Tytgat, H., Derom, F., and Galinsky, A. (1958). Acta chir. belg., 57, 188.

\section{INTERMITTENT CLAUDICATION DUE TO CYSTIC DEGENERATION OF POPLITEAL ARTERY}

BY

\section{DEREK G. LAMBLEY, M.B., B.Sc., F.R.C.S. Northampton General Hospital}

Since Atkins and Key (1947) reported a case of myxomatous tumour arising in the adventitia of the left external iliac artery in 1946, only six other cases of this condition have been reported. In four of these the popliteal artery was the site of the degeneration (Ejrup and Hiertonn, 1954 ; Hiertonn, Lindberg, and Rob, 1957).

\section{Case Report}

A master builder aged 47 was first seen in June, 1962, complaining of cramp in the left leg when he walked 50 yards, which was relieved by four to five minutes' rest. The intermittent claudication had been present for six weeks and was of sudden onset. He found himself unable to mow his lawn or to climb ladders at work. He sought medical advice and was prescribed bed rest, anticoagulants, and antispasmodics for two weeks. When he resumed activity at the end of this time the pain was rather worse than before. I first saw him six weeks after the onset of his symptoms, when the limb appeared completely normal at rest. Femoral, popliteal, dorsalis pedis, and posterior tibial pulses were all easily palpable and equal in volume compared with those of the normal limb. The popliteal artery on the left side was easily palpable and appeared to be more prominent and broader than the right artery. A provisional diagnosis of popliteal aneurysm was made and he was admitted to Northampton General Hospital for investigation.

Wassermann reaction and Reiter's complement-fixation test were negative. There was some evidence of mitral stenosis and the blood-pressure was $154 / 76$. A percutareous left femoral arteriogram, performed on July 2 , revealed a little narrowing of the femoral artery just above the femoral condyle with a rather abrupt deviation of the vessel laterally at this level. Otherwise the appearances were normal. There was no evidence of obstruction or arteriosclerotic lesion, and the appearances were said to favour an extrinsic pressure rather than an intrinsic vascular lesion (Fig. 1).

In view of the clinical abnormality of the popliteal artery its exploration seemed justifiable, since I felt there was interference with the arterial circulation at this level in spite of the comparatively normal arteriographic picture.

Operation.-The left popliteal fossa was explored under general anaesthesia (Dr. F. F. Waddy) on July 4. The popliteal artery showed a bluish uniform enlargement over a distance of $5 \mathrm{~cm}$., the greatest thickness of which was $2 \mathrm{~cm}$. The whole tumour pulsated. The upper limit of abnormality appeared to be at the lower end of Hunter's canal, the lower limit about $1.5 \mathrm{~cm}$. above the arterial bifurcation. The condition was not recognized as a cystic degeneration of the popliteal artery and was regarded as an aneurysm. It was resected with as little 